\title{
A Behavioral Genetic Test of the Evolutionary Taxonomy
}

\author{
Brian B. Boutwell ${ }^{1} \cdot$ Joseph L. Nedelec $^{2} \cdot$ Richard H. Lewis $^{3}$ - J. C. Barnes ${ }^{2}$. \\ Kevin M. Beaver ${ }^{4,5}$
}

Published online: 3 September 2015

(C) Springer International Publishing 2015

\begin{abstract}
Life-course-persistent (LCP) offending has been intensely studied over the last several decades resulting in an impressive amount of evidence linking chronic offending with a host of negative outcomes including violence, impulsiveness, and sexual promiscuity. Although much evidence also exists regarding the origins of LCP offending, emergent work is attempting to unify this knowledge under the umbrella of evolutionary biology using life history theory. The current study draws on this work - specifically, the Evolutionary Taxonomy - in order to further probe the etiology of chronic antisocial behavior. Using quantitative genetic methods and data from a national sample of twins, the current study examines whether LCP offending and the life history trait of sexual promiscuity might be linked at an underlying genetic level.
\end{abstract}

This research uses data from Add Health, a program project designed by $\mathrm{J}$. Richard Udry, Peter S. Bearman, and Kathleen Mullan Harris and funded by a grant P01-HD31921 from the Eunice Kennedy Shriver National Institute of Child Health and Human Development, with cooperative funding from 17 other agencies. Special acknowledgment is due Ronald R. Rindfuss and Barbara Entwisle for assistance in the original design. Persons interested in obtaining data files from Add Health should contact Add Health, Carolina Population Center, 123 W. Franklin Street, Chapel Hill, NC27516-2524 (HYPERLINK “javascript:main.compose('new', 't= addhealth@unc.edu')"addhealth@unc.edu). No direct support was received from grant P01-HD31921 for this analysis.

Brian B. Boutwell

boutwellb@slu.edu

Saint Louis University, St. Louis, MO, USA

2 University of Cincinnati, Cincinnati, OH, USA

Sam Houston State University, Huntsville, TX, USA

4 Florida State University, Tallahassee, FL, USA

5 King Abdulaziz University, Jeddah, Saudi Arabia
Analyses of the National Longitudinal Study of Adolescent to Adult Health (Add Health) data suggest that a shared genetic scaffold might be responsible for some of the covariation of LCP offending with the life history trait of sexual promiscuity. Specifically, the current analyses revealed evidence that overlapping genetic factors influenced both sexual involvement and LCP offender classification. Our results offer insight regarding the evolution of the traits that distinguish LCP offenders from the rest of the population. LCP offending may represent a set of life history traits that, over the course of human evolution, clustered together in small segments of the population. The findings lend support for the Evolutionary Taxonomy proposed to explain the ultimate origins of criminal offending.

Keywords Evolutionary taxonomy $\cdot$ Behavior genetic . Life-course persistent offenders

Beginning largely with Darwin (Buss 1991; Rushton 1985), a growing number of scholars have placed heavy emphasis on describing the role of natural selection in shaping human behavior and personality. While there has been an abundance of theorizing about the role of evolution in shaping various mental outcomes (cf. Buss and Hawley 2011 edited volume), the work of Rushton $(1985,2000,2004)$, in particular, has generated a host of testable hypotheses and inspired a significant amount of empirical scrutiny (Boutwell et al. 2013; Figueredo et al. 2005). In his original work, Rushton (1985) employed life history theory to explain the emergence of individual differences across a host of traits ranging from fecundity and mortality to temperament and general cognitive abilities in humans (Rushton 2000).

Research in criminology, a field traditionally hostile to biological theorizing (Barnes et al. 2014; Ellis 1988; Ellis and Hoskin 2015), has also begun drawing on Rushton's work in 
order to explain consistently observed patterns in criminal offending (Boutwell et al. 2013; Ellis 1988; Ellis and Hoskin 2015; Mishra and Lalumière 2008; see also Camilleri 2012; Camilleri and Stiver 2014; Lalumière et al. 2008 for additional evolutionary treatments of chronic criminality, as well as the evolution of related phenotypes like psychopathy). At a proximal level (where most criminological theorizing has focused), Moffitt $(1993,2006)$ offered evidence that there are at least two groups of offenders in the population: life-coursepersistent (LCP) offenders and adolescence-limited (AL) offenders. A key point in Moffitt's (1993) argument was that AL offending was thought to arise via a different developmental pathway than LCP offending. AL offenders were said to follow an age normative track where offending behaviors began increasing around puberty (and declining thereafter). LCPs, alternatively, display early-onset behavioral problems resulting from the convergence of neurological deficits and severe environmental adversity (Moffitt 1993, 2006).

Despite a wealth of support for Moffitt's (1993, 2006) work, years passed without much effort to place the theory in the context of human evolution. Recently, though, scholars have taken steps in this direction (Boutwell et al. 2013; Camilleri 2012; Camilleri and Stiver 2014; Lalumière et al. 2008, 2005). Drawing on the work of Rushton (1985) and Ellis (1988), Boutwell et al. (2013) proposed the "Evolutionary Taxonomy" in which they suggested that the existence of offender typologies represented a disproportionate clustering of certain traits within a small segment of the population. Humans display slow life history traits in general as evidenced by the fact that we reach sexual maturity slowly, have relatively few offspring, and engage in heavy parental investment (Rushton 2000). Within the framework of the Evolutionary Taxonomy, Boutwell et al. (2013) ${ }^{1}$ argued that LCP offending, in particular, represented a divergence from the average life history speed typically observed among most humans. LCP offending was thought to entail a collection of "faster" life history traits given the tendency for LCPs to engage in high sexual output (including fathering large numbers of children), to offer minimal levels of parental investment, to display broad neurocognitive impairments, and to display a general propensity for violent behavior (Moffitt 2006; Moffitt et al. 2002) .

Despite some supportive evidence for the Evolutionary Taxonomy (Boutwell et al. 2013), there are a number of unaddressed questions. For example, Boutwell and colleagues (2013) revealed that in line with theoretical predictions, sexual promiscuity correlated with LCP offending (a finding that accords with prior research in mainstream criminology)

\footnotetext{
${ }^{1}$ Mishra and Lalumière (2008) also provided an excellent overview of how life history theory intersects with the work of Moffitt (1993) and explained the origins of antisocial behavior and criminality in the population.
}

(Farrington et al. 2009; Moffitt et al. 2002). Yet, it remains to be seen what the exact nature of that association encompasses. One possibility, implicitly suggested by the analysis of Boutwell et al. (2013), was that LCP offending directly predicts (perhaps in a causal manner) engaging in greater sexual output. There is another possibility, though, and it involves genetic influences shared between traits. To the extent that genes influence both LCP offending and sexual involvement, it is possible that the same genetic influences cut across both traits, thus driving their association at the phenotypic level (Zietsch et al. 2010), though for complex reasons see (Plomin et al. 2013; Solovieff et al. 2013). Before exploring this issue directly, we briefly reflect on life history theory as well as differential $K$ theory (Rushton 1985), as this work provided the springboard for the Evolutionary Taxonomy.

\section{Understanding Life History and Differential $K$ Theory}

Life history theory is a key part of evolutionary biology, providing an explanation for differences in species- and individual-level strategies related to the speed of maturation, efforts devoted to finding a mate and copulating with them, and the time invested in parental care once an offspring is born (i.e., somatic, mating, and parental effort; Chisholm 1993; Stearns 1992). According to the theory, various evolved strategies are differentially implemented in accordance with the evolutionary history of the species and, to some extent, based on the stability or predictability of the organisms' current environment (Belsky et al. 1991; Figueredo et al. 2005, 2006, 2013; Stearns 1992).

In the context of life history theory, between-species variation in strategies relating to survival and reproduction can be placed on a continuum from "slow" to "fast" (Belsky et al. 1991; Brumbach et al. 2009). This continuum has also been referred to as the $r / K$ spectrum, where $r$-selected species tend to expend more energy on mating effort with low parental investment and increased fecundity, matching a fast reproductive strategy, whereas $K$-selected species tend toward a reproductive strategy characterized by high parental investment and decreased fecundity (Rushton 2000, 2004). While these life history strategies are species-typical, individual variation (owing to both genetic as well as environmental variation) locates organisms either closer to, or further from, the $K$ end of the life history spectrum (Brumbach et al. 2009; Dunkel et al. 2013; Figueredo et al. 2004; Wilson and Daly 1997).

A key component of $r / K$ theory is that individuals within a species will exhibit variation in terms of behavioral and physiological traits and engage in a cluster of behaviors that represent a faster $(r)$ or slower $(K)$ life history strategy (Dunkel et al. 2013; Figueredo et al. 2013). Therefore, while humans will 
exhibit a $K$-selected (i.e., slow) reproductive strategy when compared to members of other species, some will engage in behaviors that appear more in line with a faster life history repertoire when compared to other humans (Rushton 2000, 2004). Interspecies comparisons will indicate that humans are relatively $K$-selected, but intraspecies comparisons among humans will reveal a large amount of variance in levels of $K$ selected traits. Recognition of this variation in life history speed led Rushton (1985) to term his approach differential $K$ theory. This nomenclature is more appropriate than $r / K$ when applied to analyses of human behavior as evolutionary processes have pushed all humans toward the $K$ end of the $r / K$ continuum (i.e., no human would be considered to be $r$ selected).

Research applying life history theory within the social sciences has increased substantially over the past two decades (Figueredo et al. 2013; Kruger et al. 2015). Empirical analyses assessing the validity of the conceptual framework of life history theory have shown considerable support for the perspective (Brumbach et al. 2009; Dunkel and Decker 2010; Figueredo et al. 2006, 2013). In addition to construct validity analyses, the empirical literature has illustrated variance in human life history strategies related to outcomes such as health-related measures (Ellis 1988; Rushton 2000, 2004), relationship measures (Olderbak and Figueredo 2010), personality (Figueredo et al. 2007; Gladden et al. 2009), risktaking propensities (Ellis et al. 2012; Figueredo et al. 2005; Wilson and Daly 1997), and antisocial behaviors (Boutwell et al. 2013; Daly and Wilson 2005; Dunkel et al. 2010, 2013; Ellis 1988; Ellis et al. 2012; Rowe et al. 1997; Rushton 1989; Rushton and Templer 2009; Wenner et al. 2013; Wilson and Daly 1997). Importantly, given the explicit focus on reproductive behaviors within life history theory, an expanding literature has illustrated considerable within-species variance in sexual behaviors among humans congruent with expectations derived from life history theory (Boutwell et al. 2013; Figueredo et al. 2006; Rowe et al. 1997).

\section{The Evolutionary Taxonomy: a Brief Description}

As we mentioned above, Boutwell and colleagues (2013) drew on the work of Rushton $(1985,1989)$ and Ellis (1988) in order to propose their Evolutionary Taxonomy. The work of Ellis (1988) had begun examining the intersection of criminal behavior and life history theory. Observing that crime-prone individuals tend to similarly display a number of relevant life history traits, Ellis (1988) argued that criminality might be underpinned by the faster life history styles of some members of the population. Boutwell et al. (2013) argued for broadening the scope of this work in order to accommodate more recent descriptions of criminal offending (see also Mishra and Lalumière 2008). Ellis's (1988) ideas were expanded to account for Moffitt's (1993) argument that multiple groups exist in the population including complete abstainers from crime, adolescence-limited (AL) offenders, and persistent (LCP) offenders.

Boutwell and colleagues (2013) argued that abstainers and ALs embodied traits and temperaments corresponding more closely to the average human life history speed. LCPs, on the other hand, are expected to present a cluster of faster life history traits (Moffitt et al. 2002). In an earlier test of their arguments, Boutwell et al. (2013) analyzed data from the National Longitudinal Study of Adolescent to Adult Health (Add Health) and revealed that LCP offending predicted greater sexual involvement (i.e., higher mating output), a finding that dovetails with research conducted outside of the USA in other populations (Moffitt et al. 2002). The overarching argument of the Evolutionary Taxonomy, then, is that a small number of individuals in the population display a faster life history style than other humans (Boutwell et al. 2013). When considered in the present context, we expect LCP offenders to display traits that are closer to $r$ than the rest of the population.

\section{Specific Predictions from the Evolutionary Taxonomy}

One issue that Boutwell and colleagues (2013) did not fully address concerns the question of why LCP classification correlated with increased sexual involvement. It is perhaps reasonable to argue that LCP offending carries with it a host of traits that would directly (in a causal fashion) impact the risk of sexual promiscuity (Moffitt et al. 2002). An additional possibility, though, is that underlying genetic factors influencing both traits contribute to their correlation at the phenotypic level (Zietsch et al. 2010). This possibility, of course, hinges on the assumption that both sexual involvement and chronic criminality are heritable outcomes (a point which we address below). Without the use of a genetically sensitive research design, it is impossible to discern the role that genetic factors play in both traits (Barnes et al. 2014). Prior research, though, has offered some reason to suspect that shared genetic influences are implicated in the relationship between high sexual involvement and LCP offending.

Barnes et al. (2011) examined the offender groups proposed by Moffitt (1993) and found significant heritability estimates for membership across each offender category. The heritability for LCP offending, in particular, hovered at or above 0.50 (Barnes et al. 2011). This is key because if LCP offending was the product of purely environmental influences, it would be illogical to investigate whether genetic factors drove its correlation with another trait. Boutwell and Boisvert (2014) examined a sexual involvement measure contained in the Add Health data and reported a moderate heritability estimate. Zietsch and his colleagues (2010) 
uncovered similar results (regarding the heritability of sexual involvement) using a sample of Australian participants. Also of interest, Zietsch et al. (2010) revealed evidence of shared genetic effects cutting across both sexual involvement and personality traits related to sexual behaviors. Finally, at the molecular level, Beaver and colleagues (2008) found evidence that a particular genetic variant in the dopaminergic system (DAT1) predicted both number of sexual partners as well as criminogenic behavior.

\section{The Current Study}

Based on the research mentioned above, the primary hypothesis of the current study is that a shared genetic influence may exist between sexual promiscuity (i.e., mating effort) and LCP offending. Using data drawn from a large national sample within the USA, we examine the possibility that correlated genetic factors explain at least some of the covariance in LCP offending and reproductive output for participants in the sample. Ultimately, if similar genetic factors are driving the association between reproductive effort (i.e., time spent pursuing sexual partners) and LCP status, it would shed further insight as to why these traits began to cluster over time, and why current research has observed their covariance in modern humans. A larger goal, then, is to further illustrate the applicability of evolutionary thought to current conceptions of the origins of crime and other disreputable behaviors.

\section{Methods}

We utilized data collected as part of the National Longitudinal Study of Adolescent to Adult Health (Add Health) to further examine the role of life history evolution in the origins of LCP offending. Analysis of the Add Health has expanded rapidly over the past decade, and numerous studies have disseminated the sample plan and design of these data (Harris 2009). We restrict our overview to an abbreviated discussion of the Add Health sample. Participants in the study were recruited during adolescence (most were in high school, with some still in middle school). During wave I $(N=20,745$; ages $11-21)$ in 1994 and 1995, respondents completed an in-home (as well as an initial school based) survey pertaining to a host of developmental outcomes. Wave II $(N=14,738$; ages $11-23)$ followed roughly 1 year later while wave III $(N=15,197$; ages 18-28) was completed 5 years later in 2002. Most recently, wave IV $(N=15,701$; ages 24-34) was completed in 2008. In this study, we analyze data from all four waves using a subsample of twins nested within the larger sample of participants. Data collection in the Add Health ultimately compiled information from approximately 500 monozygotic (MZ) twins and 900 dizygotic (DZ) twins (Harris et al. 2013).

\section{Measures}

Sexual Promiscuity Participants taking part in the Add Health provided information concerning their lifetime sexual involvement during the wave IV interviews. Respondents were asked specifically: "With how many partners have you ever had vaginal intercourse, even if only once?" Recall that the argument in the current study is that LCP offenders represent a segment of the population that embodies a faster life history style. To capture this, it was necessary to construct a measure directly tapping an extreme effort aimed at mating. Thus, the number of lifetime partners question was dichotomized to create a measure of high sexual promiscuity (i.e., high reproductive output). To capture extreme levels of sexual involvement, those respondents scoring above the 90th percentile were coded as " 1 " and those scoring below the $90^{\text {th }}$ percentile were coded as " $0 . "$

LCP Offender Several prior studies have offered in-depth treatments regarding the creation of the LCP measure (Barnes et al. 2011; Boutwell et al. 2013). In order to preserve space, we offer only a brief description. First, a scale of each respondent's involvement in delinquency across three waves of data collection in the Add Health was created. To illustrate, during the first wave, each Add Health participant answered questions regarding how often they committed different types of delinquent acts in the past year. Respondents provided information concerning 17 types of aberrant behavior, including minor delinquency (e.g., painting graffiti and lying to their parents) and more serious criminal acts (e.g., shoplifting and using a weapon in a fight). Responses were coded so that $0=$ never, $1=$ one or two times, $2=$ three or four times, and $3=$ five or more times and were then summed to create the delinquency index at wave I. Identical procedures were also carried out for waves II and III (i.e., a delinquency/ criminal behavior scale was also generated for waves II and III). ${ }^{2}$

Next, we generated a new variable where a "1" was assigned to all respondents who had a score of "2" or higher on all three of the delinquency scales which tapped involvement in antisocial or criminal acts over the first three waves of data collection (which spanned roughly 7-8 years). The coding scheme thus provided an indicator of life course offending in that a score of "1" identified LCP offenders ( $\approx 10 \%$ of the sample). Respondents who did

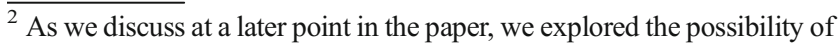
including all four waves of data when constructing the LCP measure. The benefit of this approach would have been to expand the scope of the measure by including a longer stretch of the life course. Perhaps not surprisingly (given the rarity of the trait), doing so further diminished the number of LCP offenders in the data set, drastically limiting our sample size. As a result, we opted to use the first three waves of data to construct the LCP measure.
} 
not score a "2" or higher on the three delinquency scales were assigned a value of " 0 " (respondents with a missing value on any of the three delinquency scales were assigned a missing value, and these respondents were omitted from the analyses that follow).

LCP Genetic Risk Scale A latent measure of genetic risk was created by relying on a strategy designed by prior researchers (Jaffee et al. 2005; Kendler et al. 1995) and used increasingly among a growing body of scholars (Beaver et al. 2011; Vaske et al. 2011). The first step in creating the measure involved randomly selecting one child from within each twin pair and designating that individual to be the target twin (i.e., proband). The target individual's sibling was then assigned the designation of cotwin. MZ target siblings with a co-twin scoring " 1 " on the LCP measures (i.e., they were an LCP offender) were assigned a score of " 3 " on the genetic risk scale, representing the highest level of genetic risk. DZ twins whose co-twin scored " 1 " on the LCP measure were assigned a score of " 2 , " followed by DZ twins with a co-twin scoring "0" on the LCP measure who were assigned a " 1 ". Finally, MZ twins with a co-twin scoring " 0 " on the LCP measure were assigned a score of " 0 ", representing the lowest level of genetic risk for LCP offending in the sample (see Table 1). The logic underpinning this approach is rooted in the fact that $\mathrm{MZ}$ twins share virtually all $(100 \%)$ of their genetic material, while DZ twins share, on average, half (50\%) of their distinguishing genetic material. To the extent that a particular trait is heritable, then, we would expect that an $\mathrm{MZ}$ twin reporting a co-twin with that particular trait would be at a greater level of genetic risk compared to DZ twins. This assumption rests on whether the measure used to create the genetic risk scale (i.e., the LCP measure) is heritable. Barnes et al. (2011) were the first to conduct a behavior genetic analysis on this measure and found that a substantial amount of the variance in the liability for LCP offending was accounted for by genetic factors (see also Schwartz and Beaver 2013 supporting our use of the LCP genetic risk scale). We also reanalyze the heritability of the LCP measure below.

Table 1 Logic of genetic risk scale construction

\begin{tabular}{lll}
\hline $\begin{array}{l}\text { Pair type } \\
\text { (genetic relatedness) }\end{array}$ & $\begin{array}{l}\text { Co-twin score } \\
\text { on focal variable }\end{array}$ & $\begin{array}{l}\text { Target sib's } \\
\text { genetic risk score }\end{array}$ \\
\hline MZ (1.00) & 1 & 3 \\
DZ (0.50) & 1 & 2 \\
DZ (0.50) & 0 & 1 \\
MZ (1.00) & 0 & 0 \\
\hline
\end{tabular}

For the current study, the focal variable is either the dichotomous sexual promiscuity measure or the dichotomous LCP measure
Sexual Promiscuity Genetic Risk Scale A nearly identical logic and coding strategy was utilized when creating the genetic risk scale for sexual promiscuity. Employing the dichotomous sexual promiscuity item, a coding scheme mirroring the one described above was carried out. Specifically, MZ twins with a co-twin scoring a " 1 " on the dichotomous sexual promiscuity measure were assigned a score of " 3 " on the genetic risk scale. DZ twins whose co-twin scored " 1 " on the sexual promiscuity measure were assigned a score of " 2 ", followed by DZ twins with a co-twin scoring " 0 " on the sexual promiscuity measure who were assigned a " 1 ". Finally, MZ twins with a co-twin scoring " 0 " on the sexual promiscuity measure were assigned a score of " 0 " (see Table 1).

\section{Analytical Strategy}

The analysis in the current study was executed in a series of steps. First, we examined the cross-sibling similarity of the LCP and sexual promiscuity measures across levels of genetic relatedness for participants in the sample. This first step was necessary to identify a pattern of findings known as a "genetic cascade" (Plomin et al. 2013) where MZ twins display greater similarity for a particular phenotype compared against DZ twins (Barnes et al. 2014). Should this be the case, it provides initial evidence that a particular trait is under genetic influence. Second, we directly examined the heritability of both the LCP and sexual promiscuity measures by calculating an ACE model using the software package Mplus (see the work of Muthèn and Muthèn 2012; Neale and Maes 2004; Plomin et al. 2013 for extensive discussion of ACE modeling specifically and quantitative genetic techniques in general). Briefly, ACE models utilize structural equation modeling techniques in order to decompose phenotypic variance into that which is due to genetic factors (A), that which is due to the common environment $(\mathrm{C})$, and that which is due to the non-shared environment, as well as measurement error (E) (Neale and Maes 2004). Nested models are also estimated by dropping either the $\mathrm{A}$ or the $\mathrm{C}$ term and comparing model fit of the AE or CE models against the full ACE model (Neale and Maes 2004). The best fitting model is selected based on model fit statistics (e.g., model chi-squared $\left[X^{2}\right]$ ).

The final step was to test whether the genes that impact sexual promiscuity might overlap with the genes that impact LCP offending. For this step, we used the genetic risk scales described above and examined the impact of each (the LCP and sexual promiscuity genetic risk scales) on the outcomes of LCP classification and sexual promiscuity using path models estimated in Mplus. In short, we tested whether the genetic risk scale for sexual promiscuity predicted LCP offending and vice versa. Our results are presented below. 


\section{Results}

Descriptive statistics are provided in Table 2. Table 3 begins to address the question of whether sexual promiscuity and LCP offending are under genetic influence. The results in Table 3 reveal evidence of a genetic cascade in which MZ twins tend to resemble one another more closely than do DZ twins for the measure of LCP offending and for the measure of sexual promiscuity. Figure 1 displays this pattern graphically, presenting the predicted probabilities of classification as an LCP offender, or as sexually promiscuous, for the target twin based on the status of his/her co-twin. The next step was to directly calculate the heritability estimates for each of the measures. ACE model results (presented in Table 4) revealed that the best fitting model was the AE model for both the LCP measure and sexual promiscuity. Heritability and the non-shared environment accounted for all of the variance in both variables. LCP offender classification was roughly $79 \%$ heritable, and sexual promiscuity was approximately $50 \%$ heritable. Knowing that each of the measures in the study is at least partly heritable allowed us to proceed to the final step in the analytical process: examining whether similar genes might be influencing both traits.

For this last step, we utilized the genetic risk scales created for both variables to predict the LCP and sexual promiscuity variables. The genetic risk scale for sexual promiscuity was used to predict the LCP measure, and the genetic risk scale for LCP offending was used to predict the sexual promiscuity measure (and the two genetic risk scales were set to covary with one another). Figure 2 contains the results from this portion of the analysis, and the results support the prediction that shared genetic factors influence both LCP offending and sexual involvement. Not only did the genetic risk scales covary with one another, but they were also significantly predictive across traits. We discuss our findings, along with potential limitations, in more detail below.

\section{Discussion}

The current study was intended to further unpack the nature and origins of LCP criminal behavior. Ellis (1988) was one of the first scholars to draw attention to the fact that a variety of

Table 2 Descriptive statistics for study variables

\begin{tabular}{lllll}
\hline & Proportion (mean) & SD & Min & Max \\
\hline Sexual promiscuity & 0.095 & - & 0 & 1 \\
LCP offender & 0.072 & - & 0 & 1 \\
Genetic risk: sexual promiscuity & $(0.768)$ & 0.702 & 0 & 3 \\
Genetic risk: LCP offender & $(0.737)$ & 0.673 & 0 & 3 \\
\hline
\end{tabular}

important life history traits correlate with criminal outcomes. These associations may have emerged because of selection forces acting to locate humans along a spectrum ranging from either more, or less, $K$ selected (i.e., faster versus slower life histories; Rushton 2000). Because numerous genes underpin life history traits (Figueredo et al. 2006), we might reasonably predict that genetic influences of one trait may correlate with the genetic influences of another. Our findings are consistent with this argument, and analysis of sibling pairs contained in the Add Health data revealed evidence that correlated genetic factors influence both LCP offending and extreme sexual involvement. This finding suggests the existence of pleiotropic genetic effects. As others have pointed out, though, we cannot reach a definitive conclusion about pleiotropy owing to data limitations, which preclude ruling out alternative explanations (Duffy and Martin 1994; Falconer and Mackay 1996; Solovieff et al. 2013; Zietsch et al. 2010).

With the above in mind, it would be hasty to conclude this study without recognizing the inherent limitations - both theoretical and methodological - that we faced. First, it is possible that sexual promiscuity and LCP offending correlate for reasons other than life history selection. Prior scholars have provided excellent overviews in this regard (see, for instance, Lalumière et al. 2008; Mishra and Lalumière 2008). One trait, in particular, psychopathy, deserves additional attention, as it may be implicated in the pattern of findings obtained in the current study. Prior researchers have suggested that psychopathy itself may represent a reproductive strategy shaped by natural selection (Glenn et al. 2011; Lalumière et al. 2008; Mishra and Lalumière 2008). This becomes important for the current study because LCP offenders are also more likely to evince psychopathic personality styles than are other members of the population (Moffitt et al. 2002). Other scholars (see, for instance, Mishra and Lalumière 2008) have also argued that psychopathy represents a third, and distinct, pathway to offending separate from LCP offending with a distinct (partially genetic) etiology (psychopathy is also heritable [Beaver et al. 2011; Blonigen et al. 2003]).

Though we attribute our results to shared genetic factors influencing both LCP offending and sexual involvement, our measure of LCP offending might actually function as somewhat of a proxy for psychopathic personality styles. Indeed, it is a statistical probability that the traits captured in our LCP measure do reflect traits present in individuals who score high on a measure of psychopathy (Moffitt et al. 2002). It is important to consider, though, that not all LCP offenders are psychopathic (in a clinical sense) and not all psychopathic individuals will meet the definition of an LCP offender. Moreover, only about $1 \%$ of the population is diagnosable as psychopathic whereas roughly 5 to $10 \%$ of the populace will exhibit chronic criminality (Glenn et al. 2011; Moffitt et al. 2002). As a result, to conclude definitively that our findings are being driven solely by psychopathy would be unwarranted and 
Table 3 Probandwise concordance rates, tetrachoric correlations, and odds ratios

\begin{tabular}{|c|c|c|c|c|c|c|c|c|}
\hline & \multicolumn{4}{|c|}{ Sexual promiscuity } & \multicolumn{4}{|c|}{ LCP offender } \\
\hline & Prevalence & Concordance & Correlation & Odds Ratio & Prevalence & Concordance & Correlation & Odds ratio \\
\hline All twins & 0.095 & $22 / 94(0.234)$ & $0.352^{*}$ & $3.514^{*}$ & 0.072 & $20 / 59(0.339)$ & $0.605^{*}$ & $10.888^{*}$ \\
\hline MZ twins & 0.080 & $8 / 29(0.276)$ & $0.483^{*}$ & $6.168^{*}$ & 0.074 & $10 / 23(0.435)$ & $0.744^{*}$ & $19.645^{*}$ \\
\hline DZ twins & 0.105 & $14 / 65(0.215)$ & 0.278 & $2.627^{*}$ & 0.070 & $10 / 36(0.278)$ & $0.513^{*}$ & $7.337^{*}$ \\
\hline$X^{2}(d f=1)$ & 2.127 & - & - & - & 0.040 & - & - & - \\
\hline
\end{tabular}

${ }^{*} p<0.05$ (two-tailed)

premature. Nonetheless, this represents a fascinating empirical question that future research analyzing larger samples will be capable of addressing.

As we mentioned above, life history theory is not the only evolutionary approach that might logically explain a link between sexual output and antisocial behavior (see Lalumière et al. 2008). A variety of traits (e.g., neurocognitive functioning, general intelligence, longevity), however, cling together with LCP offending (Moffitt et al. 2002). While alternative explanations might offer a reasonable explanation for the LCP correlation with sexual promiscuity, life history theory is a particularly relevant theoretical approach given its ability to unite a host of developmental traits that also cluster among chronic offenders in the population (Ellis 1988).
The third important limitation centers on methodological concerns in the Add Health data. The twin sample available in the Add Health is large; however, examining traits that occur rarely in the population (i.e., LCP offending and extreme promiscuity) can still drastically diminish case counts. This impacted the current study in two respects. First, we considered whether to utilize all four waves of data when constructing the LCP measure-broadening the scope of the measure to include a longer stretch of the life course. Doing so diminished the number of LCP offenders in the data set, so we opted to retain the LCP measure derived from three waves of data. Second, an already diminished case count prevented the estimation of bivariate Cholesky decomposition models (Plomin et al. 2013) for the LCP and sexual promiscuity measures. Cholesky models are useful because they partition the
Fig. 1 Predicted probabilities of target twin status based on cotwin status
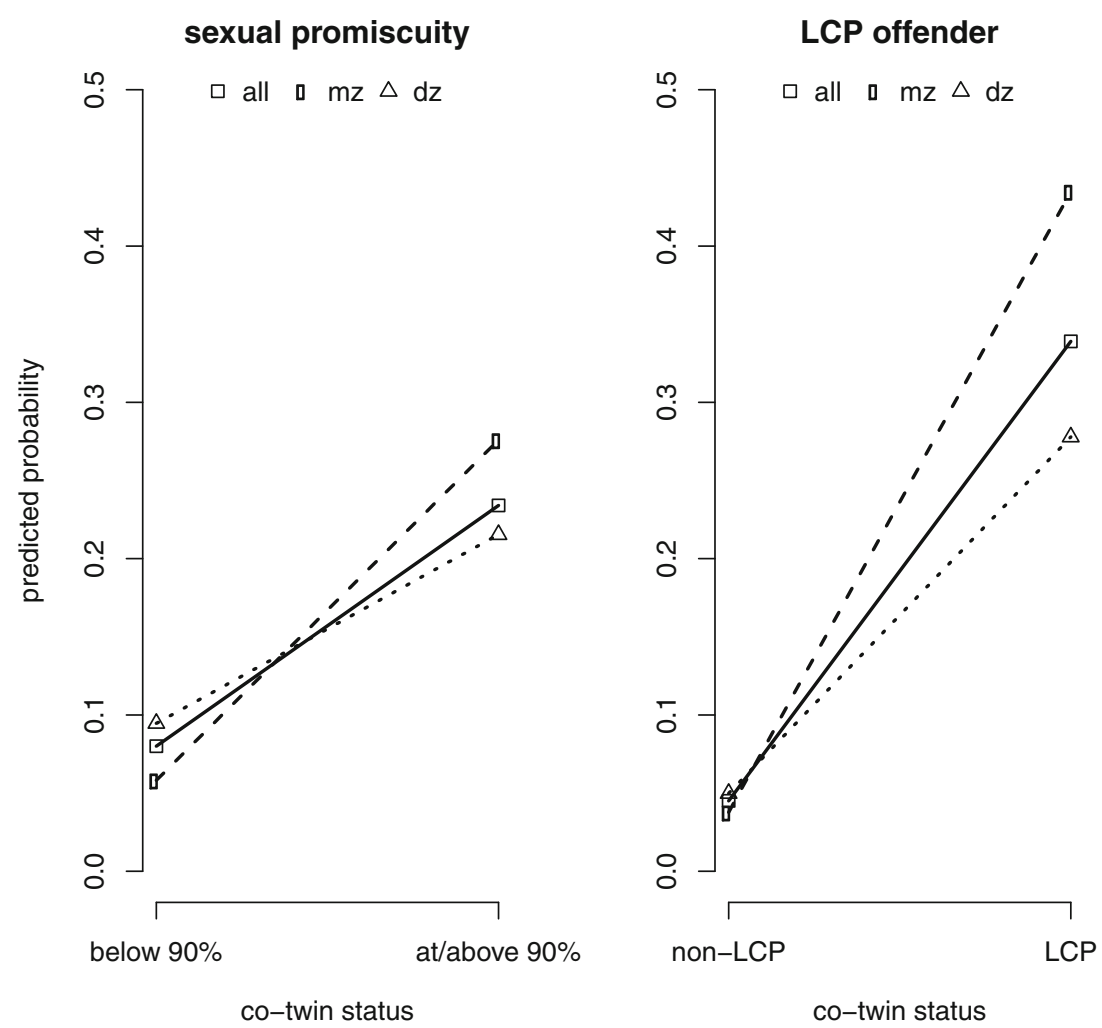
Table 4 ACE model parameter estimates

\begin{tabular}{|c|c|c|c|c|c|c|}
\hline & \multicolumn{3}{|c|}{ Parameter estimates } & \multicolumn{3}{|c|}{ Model fit statistics } \\
\hline & A & $\mathrm{C}$ & $\mathrm{E}$ & $\Delta X^{2}$ & $\Delta d f$ & WRMR \\
\hline \multicolumn{7}{|c|}{ Sexual promiscuity } \\
\hline ACE & 0.429 & 0.062 & 0.509 & - & - & 0.859 \\
\hline $95 \% \mathrm{CI}$ & $(-0.445-1.303)$ & $(-0.583-0.707)$ & $(0.169-0.849)$ & & & \\
\hline $\mathrm{AE}$ & 0.508 & - & 0.492 & 0.035 & 1 & 0.866 \\
\hline $95 \% \mathrm{CI}$ & $(0.219-0.797)$ & - & $(0.203-0.781)$ & & & \\
\hline $\mathrm{CE}$ & - & 0.361 & 0.639 & 0.926 & 1 & 1.022 \\
\hline $95 \% \mathrm{CI}$ & - & $(0.147-0.574)$ & $(0.426-0.853)$ & & & \\
\hline \multicolumn{7}{|c|}{ LCP offender } \\
\hline $\mathrm{ACE}$ & 0.468 & 0.284 & 0.248 & - & - & 0.921 \\
\hline $95 \%$ CI & $(-0.283-1.219)$ & $(-0.345-0.914)$ & $(0.011-0.485)$ & & & \\
\hline $\mathrm{AE}$ & 0.792 & - & 0.208 & 0.786 & 1 & 1.054 \\
\hline $95 \% \mathrm{CI}$ & $(0.573-1.012)$ & - & $(-0.012-0.427)$ & & & \\
\hline $\mathrm{CE}$ & - & 0.659 & 0.341 & 1.489 & 1 & 1.160 \\
\hline $95 \% \mathrm{CI}$ & - & $(0.475-0.843)$ & $(0.157-0.525)$ & & & \\
\hline
\end{tabular}

Best-fitting model in italics

$95 \%$ CI $95 \%$ confidence interval, WRMR weighted root-mean-square residual

covariance between measures into that which is the result of shared genetic influences, helping to directly examine whether two phenotypes share genetic underpinnings (Plomin et al. 2013). Attempting to estimate these models in the current study resulted in unstable parameter estimates and extremely wide confidence intervals (owing to the fact that the phenotypes in question occur rarely in the population resulting in some cells having very low, or even zero, cases located within them). The pattern of findings from the Cholesky models did suggest that overlapping genetic factors influenced both traits. Yet, given the issues just mentioned, we opted not to present them and to retain our current plan of analysis. Future research with even larger samples will be better equipped to address this particular methodological concern.

Fourth, like all statistical methods, twin studies are subject to assumptions that, when violated, can create biased

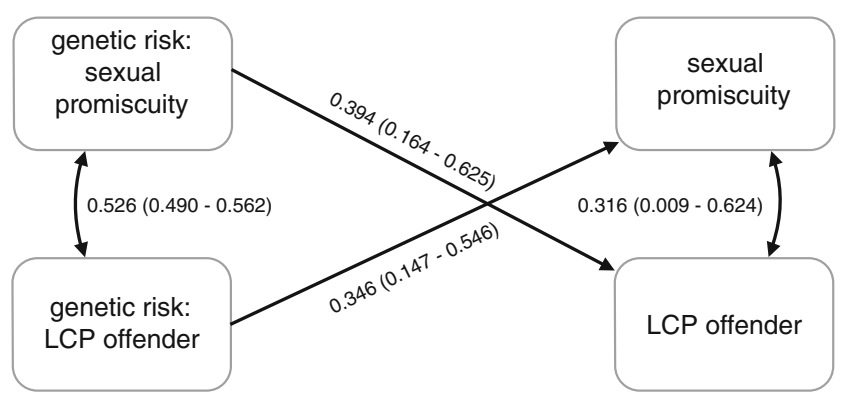

Fig. 2 Examining the shared genetics of LCP offending and sexual promiscuity. Unstandardized logistic regression coefficients are presented along single-headed arrows and correlations are presented along double-headed arrows; $95 \%$ confidence intervals in parentheses; estimates were generated from single-entered data parameter estimates (Barnes et al. 2014). Despite this, recent empirical analyses and reviews of prior evidence have revealed robust support for twin methodologies and their underlying assumptions, suggesting that the use of twin samples to answer questions about behavior represents a robust research strategy (Barnes et al. 2014; Kendler et al. 2015; Wright et al. 2015). Fifth, and finally, the current analyses were based on a subset of a nationally representative sample, but not the representative sample itself. As a result, our findings might not generalize to a broader population. Barnes and Boutwell (2013) offered evidence strongly in favor of generalizability, but the extent to which our results would hold in a more representative sample remains uncertain. With these limitations in mind, we await further analysis of the Evolutionary Taxonomy in order to determine whether our findings replicate using different and larger samples.

\section{References}

Barnes, J. C., \& Boutwell, B. B. (2013). A demonstration of the generalizability of twin-based research on antisocial behavior. Behavior Genetics, 43(2), 120-131.

Barnes, J. C., Beaver, K. M., \& Boutwell, B. B. (2011). Examining the genetic underpinnings to Moffitt's developmental taxonomy: a behavioral genetic analysis. Criminology, 49(4), 923-954.

Barnes, J. C., Wright, J. P., Boutwell, B. B., Schwartz, J. A., Connolly, E. J., Nedelec, J. L., \& Beaver, K. M. (2014). Demonstrating the validity of twin research in criminology. Criminology, 52(4), 588-626.

Beaver, K. M., Wright, J. P., \& Walsh, A. (2008). A gene-based evolutionary explanation for the association between criminal 
involvement and number of sex partners. Biodemography and social biology, 54(1), 47-55.

Beaver, K. M., Barnes, J. C., May, J. S., \& Schwartz, J. A. (2011). Psychopathic personality traits, genetic risk, and gene-environment correlations. Criminal Justice and Behavior, 38, 896-912.

Belsky, J., Steinberg, L., \& Draper, P. (1991). Childhood experience, interpersonal development, and reproductive strategy: an evolutionary theory of socialization. Child Development, 62, 647-670.

Blonigen, D. M., Carlson, S. R., Krueger, R. F., \& Patrick, C. J. (2003). A twin study of self- reported psychopathic personality traits. Personality and Individual Differences, 35, 179-197.

Boutwell, B. B., \& Boisvert, D. (2014). Sexual promiscuity \& self-control: a behavior genetic explanation to an evolutionary question. Personality and Individual Differences, 63, 112-116.

Boutwell, B. B., Barnes, J. C., Deaton, R., \& Beaver, K. M. (2013). On the evolutionary origins of life-course persistent offending: a theoretical scaffold to Moffitt's developmental taxonomy. Journal of Theoretical Biology, 322, 72-80.

Brumbach, B. H., Figueredo, A. J., \& Ellis, B. J. (2009). Effects of harsh and unpredictable environments in adolescence on development of life history strategies. Human Nature, 20, 25-51.

Buss, D. M. (1991). Evolutionary personality psychology. Annual Review of Psychology, 42(1), 459-491.

Buss, D. M., \& Hawley, P. H. (Eds.). (2011). The evolution of personality and individual differences. New York: Oxford University Press.

Camilleri, J. A. (2012). Evolutionary psychological perspectives on sexual offending: from etiology to intervention. In T. K. Shackelford \& V. A. Weekes-Shackelford (Eds.), Oxford handbook of evolutionary perspectives on violence, homicide, and war (pp. 173-196). Oxford: Oxford University Press.

Camilleri, J. A., \& Stiver, K. A. (2014). Adaptation and sexual offending. In Evolutionary perspectives on human sexual psychology and behavior (pp. 43-67). New York: Springer.

Chisholm, J. S. (1993). Death, hope, and sex: life-history theory and the development of reproductive strategies. Current Anthropology, 34, $1-24$.

Daly, M., \& Wilson, M. (2005). Carpe diem: adaptation and devaluing the future. The Quarterly Review of Biology, 80, 55-60.

Duffy, D. L., \& Martin, N. G. (1994). Inferring the direction of causation in cross-sectional twin data: theoretical and empirical considerations. Genetic Epidemiology, 11, 483-502.

Dunkel, C. S., \& Decker, M. (2010). Convergent validity of measures of life history strategy. Personality and Individual Differences, 48, 681-684.

Dunkel, C. S., Mathes, E., \& Papini, D. R. (2010). The effect of life expectancy on aggression and generativity: a life history perspective. Evolutionary Psychology, 8, 492-505.

Dunkel, C. S., Mathes, E., \& Beaver, K. M. (2013). Life history theory and the general theory of crime: life expectancy effects on low selfcontrol and criminal intent. Journal of Social, Evolutionary, and Cultural Psychology, 7, 12-23.

Ellis, L. (1988). Criminal behavior and $\mathrm{r} / \mathrm{k}$ selection: an extension of gene-based evolutionary theory. Personality and Individual Differences, 9, 696-708.

Ellis, L., \& Hoskin, A. W. (2015). The evolutionary neuroandrogenic theory of criminal behavior expanded. Aggression and Violent Behavior, 24, 61-74.

Ellis, B. J., Del Giudice, M., Dishion, T. J., Figueredo, A. J., Gray, P., et al. (2012). The evolutionary basis of risky adolescent behavior: implications for science, policy, and practice. Developmental Psychology, 48, 598-623.

Falconer, D. S., \& Mackay, T. F. C. (1996). Introduction to quantitative genetics (4th ed.). Harlow: Longman Group.

Farrington, D. P., Ttofi, M. M., \& Coid, J. W. (2009). Development of adolescence-limited, late-onset, and persistent offenders from age 8 to age 48. Aggressive Behavior, 35(2), 150-163.
Figueredo, A. J., Vasquez, G., Brumbach, B. H., \& Schneider, S. M. (2004). The heritability of life history strategy: the k-factor, covitality, and personality. Social Biology, 51(3-4), 121-143.

Figueredo, A. J., Vásquez, G., Brumbach, B. H., Sefcek, J. A., Kirsner, B. R., \& Jacobs, W. J. (2005). The K-factor: individual differences in life history strategy. Personality and Individual Differences, 39, 1349-1360.

Figueredo, A. J., Vásquez, G., Brumbach, B. H., Schneider, S. M., Sefcek, J. A., et al. (2006). Consilience and life history theory: from genes to brain to reproductive strategy. Developmental Review, 26, 243-275.

Figueredo, A. J., Vásquez, G., Brumbach, B. H., \& Schneider, S. M. (2007). The K-factor, covitality, and personality. Human Nature, $18,47-73$.

Figueredo, A. J., Cabeza de Baca, T., \& Woodley, M. A. (2013). The measurement of human life history strategy. Personality and Individual Differences, 55(3), 251-255.

Gladden, P. R., Figueredo, A. J., \& Jacobs, W. J. (2009). Life history strategy, psychopathic attitudes, personality, and general intelligence. Personality and Individual Differences, 46, 270-275.

Glenn, A. L., Kurzban, R., \& Raine, A. (2011). Evolutionary theory and psychopathy. Aggression and Violent Behavior, 16(5), 371-380.

Harris, K. M. (2009). The National Longitudinal Study of Adolescent Health (Add Health), waves I \& II, 1994-1996; wave III, 20012002; wave IV, 2007-2009 [machine-readable data file and documentation].

Harris, K. M., Halpern, C. T., Haberstick, B. C., \& Smolen, A. (2013). The National Longitudinal Study of Adolescent Health (Add Health) sibling pairs data. Twin Research and Human Genetics, 16, 391-398.

Jaffee, S. R., Caspi, A., Moffitt, T. E., Dodge, K. A., Rutter, M., Taylor, A., \& Tully, L. A. (2005). Nature $\times$ nurture: genetic vulnerabilities interact with physical maltreatment to promote conduct problems. Development and Psychopathology, 17(01), 67-84.

Kendler, K. S., Kessler, R. C., Walters, E. E., MacLean, C., Neale, M. C., Heath, A. C., \& Eaves, L. J. (1995). Stressful life events, genetic liability, and onset of an episode of major depression in women. The American Journal of Psychiatry, 152, 833-842.

Kendler, K. S., Lönn, S. L., Maes, H. H., Sundquist, J., \& Sundquist, K. (2015). The etiological role of genetic and environmental factors in criminal behavior as determined from full- and half-sibling pairs: an evaluation of the validity of the twin method. Psychological Medicine, 45, 1873-1880.

Kruger, D. J., Nedelec, J. L., Reischl, T. M., \& Zimmerman, M. A. (2015). Life history predicts perceptions of procedural justice and crime reporting intentions. Evolutionary Psychological Science, 112 .

Lalumiere, M. L., Harris, G. T., Quinsey, V. L., \& Rice, M. E. (2005). The causes of rape: understanding individual differences in male propensity for sexual aggression. Washington, DC: American Psychological Association.

Lalumière, M. L., Mishra, S., \& Harris, G. T. (2008). In cold blood: the evolution of psychopathy. In J. Duntley \& T. K. Shackelford (Eds.), Evolutionary forensic psychology: Darwinian foundations of crime and law (pp. 176-197). New York: Oxford University Press.

Mishra, S., \& Lalumière, M. L. (2008). Risk taking, antisocial behavior, and life histories. In J. Duntley \& T. K. Shackelford (Eds.), Evolutionary forensic psychology: Darwinian foundations of crime and law (pp. 139-159). New York: Oxford University Press.

Moffitt, T. E. (1993). Adolescence-limited and life-course-persistent antisocial behavior: a developmental taxonomy. Psychological Review, $100(4), 674$.

Moffitt, T. E. (2006). A review of research on the taxonomy of life-course persistent versus adolescence-limited antisocial behavior. In F. T. Cullen, J. P. Wright, \& K. R. Blevins (Eds.), Taking stock: the status 
of criminological theory (pp. 277-311). New Brunswick: Transaction Publishers.

Moffitt, T. E., Caspi, A., Harrington, H., \& Milne, B. J. (2002). Males on the life-course-persistent and adolescence-limited antisocial pathways: follow-up at age 26 years. Development and Psychopathology, 14(01), 179-207.

Muthèn, L. K., \& Muthèn, B. O. (2012). Mplus user's guide (7th ed.). Los Angeles: Muthèn \& Muthèn.

Neale, M. C., \& Maes, H. H. M. (2004). Methodology for genetic studies of twins and families. Dordrecht: Kluwer Academic Publishers.

Olderbak, S. G., \& Figueredo, A. J. (2010). Life history strategy as a longitudinal predictor of relationship satisfaction and dissolution. Personality and Individual Differences, 49, 234-239.

Plomin, R., DeFries, J. C., Knopik, V. S., \& Neiderhiser, J. M. (2013). Behavioral genetics (6th ed.). New York: Worth Publishers.

Rowe, D. C., Vazsonyi, A. T., \& Figueredo, A. J. (1997). Mating-effort in adolescence: a conditional or alternative strategy. Personality and Individual Differences, 23, 105-115.

Rushton, J. P. (1985). Differential K theory: the sociobiology of individual and group differences. Personality and Individual Differences, 6 , 441-452.

Rushton, J. P. (1989). Race differences in sexuality and their correlates: another look and physiological models. Journal of Research in Personality, 23, 35-54.

Rushton, J. P. (2000). Race, evolution, and behavior: a life history perspective (3rd ed.). Port Huron: Charles Darwin Research Institute.

Rushton, J. P. (2004). Placing intelligence into an evolutionary framework or how $g$ fits into the $r$ - $K$ matrix of life history traits including longevity. Intelligence, 32, 321-328.
Rushton, J. P., \& Templer, D. I. (2009). National differences in intelligence, crime, income, and skin color. Intelligence, 37, 341-346.

Schwartz, J. A., \& Beaver, K. M. (2013). A partial test of Moffitt's developmental taxonomy: examining the role of genetic risk. Justice Quarterly, (in press), 1-24.

Solovieff, N., Cotsapas, C., Lee, P. H., Purcell, S. M., \& Smoller, J. W. (2013). Pleiotropy in complex traits: challenges and strategies. Nature Reviews Genetics, 14, 483-495.

Stearns, S. C. (1992). The evolution of life histories. New York: Oxford University Press.

Vaske, J., Wright, J. P., Boisvert, D., \& Beaver, K. M. (2011). Gender, genetic risk, and criminal behavior. Psychiatry Research, 185(3), 376-381.

Wenner, C. J., Bianchi, J., Figueredo, A. J., Rushton, J. P., \& Jacobs, W. J. (2013). Life history theory and social deviance: the mediating role of executive function. Intelligence, 41, 102-113.

Wilson, M., \& Daly, M. (1997). Life expectancy, economic inequality, homicide, and reproductive timing in Chicago neighbourhoods. BMJ, 314, 1271-1274.

Wright, J. P., Barnes, J. C., Boutwell, B. B., Schwartz, J. A., Connolly, E. J., Nedelec, J. L., \& Beaver, K. M. (2015). Mathematical proof is not minutiae and irreducible complexity is not a theory: a final response to Burt and Simons and a call to criminologists. Criminology, 53(1), 113-120.

Zietsch, B. P., Verweij, K. J. H., Bailey, J. M., Wright, M. J., \& Martin, N. G. (2010). Genetic and environmental influences on risky sexual behaviour and its relationship with personality. Behavior Genetics, 40(1), 12-21. 